07,13

\title{
Структурные изменения на поверхностях фольг вольфрама под действием одноосного растяжения
}

\author{
(C) В.Е. Корсуков, С.А. Князев, П.Н. Бутенко, В.Л. Гиляров, \\ М.М. Корсукова, И.А. Няпшаев, Б.А. Обидов
}

Физико-технический институт им. А.Ф. Иофрфе РАН, Санкт-Петербург, Россия

E-mail: vjacheslav.korsukov@mail.ioffe.ru

(Поступила в Редакцию 30 июня 2016 г.)

\begin{abstract}
Методами дифракции медленных электронов и атомной силовой микроскопии исследовалось изменение морфологии поверхности рекристаллизованной фольги $\mathrm{W}$ под воздействием одноосного растяжения в сверхвысоком вакууме. С помощью дифракции медленных электронов установлено, что под влиянием одноосного растяжения на поверхности фольги, состоящей из отдельных блоков доминирующей грани (112), происходит разворот структурных блоков. Анализ топограмм различных областей боковой поверхности разорванного образца, полученных методом атомной силовой микроскопии, позволил связать изменения атомной структуры поверхностных слоев фольги с изменением ее рельефа при механическом воздействии.
\end{abstract}

DOI: 10.21883/FTT.2017.02.44053.269

\section{1. Введение}

Уникальные свойства нанокристаллических структур, существенно отличающиеся от макрокристаллических объектов, обусловили повышенный интерес к изучению поверхности твердых тел в нанометровом масштабе [1-9]. Данная работа является продолжением экспериментов, проводимых в ФТИ им. А.Ф. Иоффе, по исследованию структурных изменений на поверхности твердых тел при механическом воздействии в сверхвысоком вакууме [10-21]. Сочетание методов дифракции медленных электронов (ДМЭ), электронной оже спектроскопии (ЭОС), позволили провести комплексное исследование трансформации атомной, электронной структур и химического состава различных материалов при механическом воздействии. С помощью зондового метода: атомной силовой микроскопии (АСM) осуществлялся контроль рельефа поверхности изучаемого материала.

Трансформации атомной структуры и рельефа поверхности металлов при термическом и механическом воздействиях представляют интерес с многих точек зрения. Например, с точки зрения гетерокатализа $[1,3,4,8]$, создания новых наноматериалов $[1,2,5,11,13,15,16]$, выяснение механизмов деформации и разрушения [9-14,16-22]. Важно это и для других направлений фундаментальной и прикладной физики [6,7].

В работах $[11-13,16]$ изучались изменения атомной структуры и поверхностного рельефа тонкой платиновой фольги в процессе рекристаллизации и одноосного растяжения в условиях сверхвысокого вакуума (CBB). Полученные результаты использовались для детализации механизмов пластической деформации и зарождения разрушения металлов с ГЦК-решеткой, а также целенаправленной модификации поверхностной морфологии для решения конкретных задач наноэлектроники и оптической спектроскопии.
Несомненный интерес представляют подобного рода эксперименты и на металлах с ОЦК-решеткой, поскольку они имеют другой тип дислокационных структур, набор плоскостей скольжения и соответственно другие механизмы деформации и разрушения, а также иные каталитические свойства поверхности [1,3,4,6-8,22]. Результаты таких экспериментов на образцах молибдена представлены в [10,20].

Целью настоящей работы является изучение морфологии (атомной структуры и рельефа) поверхности другого представителя металлов с ОЦК-решеткой - вольфрама при одноосном растяжении в СВВ.

\section{2. Объекты и методы исследования}

Исходным материалом в данной работе служили поликристаллические ленты из вольфрама чистотой 99.96\% в виде полос длиной $3 \mathrm{~cm}$, шириной $0.3 \mathrm{~mm}$ и толщиной $\sim 0.2 \mu \mathrm{m}$.

Предварительно поверхность образцов очищалась обработкой в ацетоне и изопропиловом спирте с последующей сушкой в сухом азоте. После этого образцы крепились в нагружательном устройстве и помещались в установку, где производилась их рекристаллизация и растяжение, вплоть до разрыва с одновременным контролем состояния атомной структуры и химического состава поверхности методами ДМЭ и ЭОС. Размещение устройства для механического растяжения образцов на фланце кристаллодержателя позволило наблюдать за трансформацией картин ДМЭ непосредственно в процессе различного рода внешних воздействий. Высокотемпературный прогрев образца вплоть до $\sim 2000^{\circ} \mathrm{C}$ осуществлялся пропусканием электрического тока через образец от регулируемого источника переменного напряжения. Температура нагретой полоски определялась с помощью пирометра. Напуск кислорода в дифракционную камеру осуществлялся через натекатель 

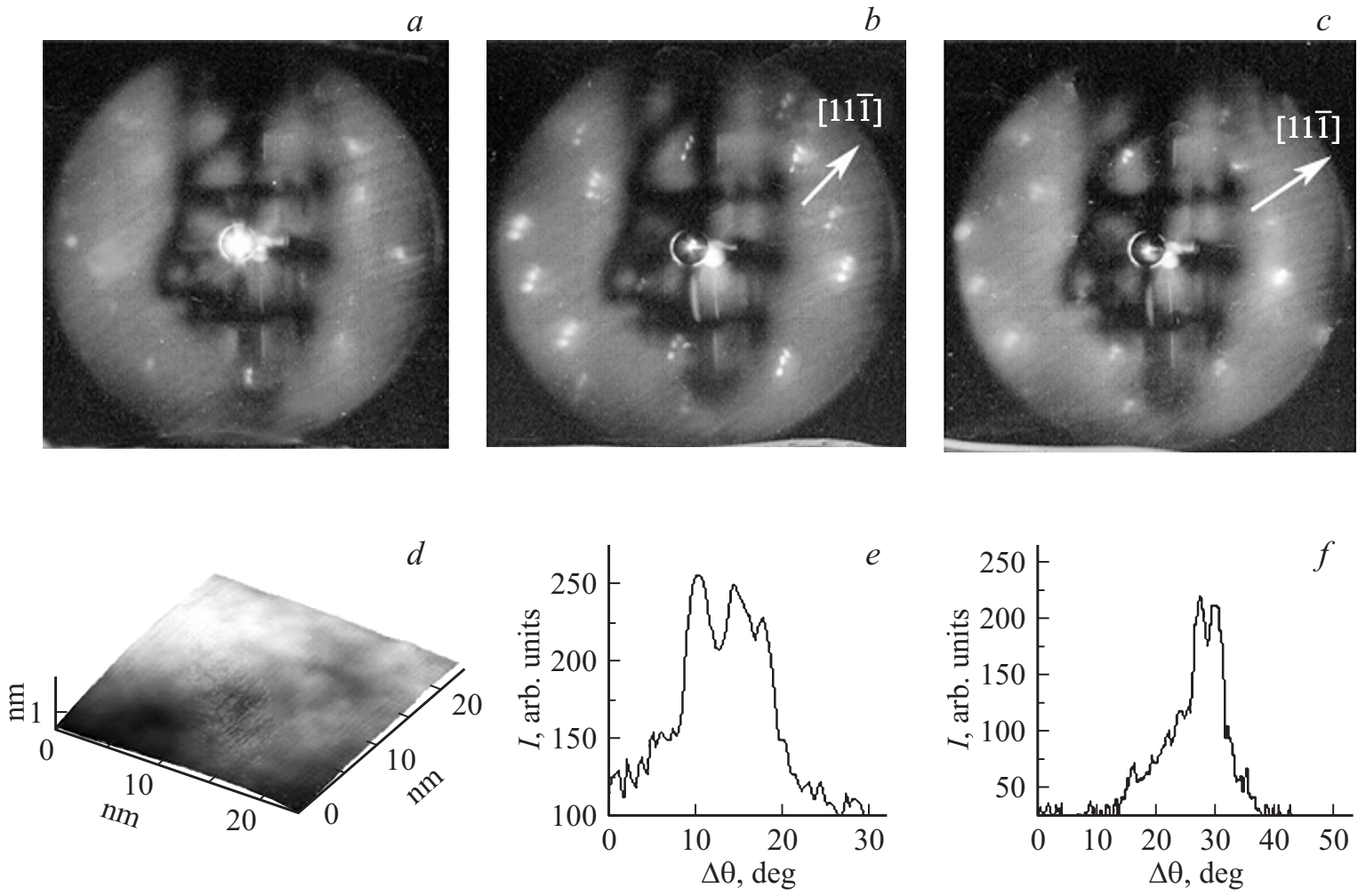

Рис. 1. Картины ДМЭ в период рекристаллизации: $a-$ начальная стадия, $b-$ конечная стадия, $c-$ под напряжением $\sigma \sim 90$ МРа, $d-\mathrm{ACM} \mathrm{изображение} \mathrm{одной} \mathrm{из} \mathrm{площадок} \mathrm{когерентности,} \mathrm{от} \mathrm{которой} \mathrm{происходит} \mathrm{дифракция,} e-$ расщепление дифракционных максимумов $(\sigma=0), f-$ в месте предполагаемого разрыва при $\sigma \sim 90 \mathrm{MPa}$.

в динамическом режиме. Более подробное описание нагружательного устройства можно найти в работе [12].

При обработке топограмм поверхности использовали фрактальный анализ $[9,19,21]$.

\section{3. Результаты эксперимента и обсуждение}

3.1. Рекристаллизация образцов в С В Процесс очистки и рекристаллизации образца состоял в серии циклов прогревов вольфрамовой полоски в вакууме и кислороде.

Типичный цикл состоял из прогрева вольфрамовой ленты в СВВ при температуре $\sim 1200^{\circ} \mathrm{C}$ в течение $1 \mathrm{~h}$. После этого образцы прогревались в кислороде при температуре $\sim 900^{\circ} \mathrm{C}$ и давлении кислорода порядка $10^{-4} \mathrm{~Pa}$ в течение $20 \mathrm{~min}$. Затем вольфрамовая полоска прогревалась в СВВ при температуре $\sim 1400^{\circ} \mathrm{C}$ в течение $5 \mathrm{~min}$. Последние циклы подготовки образцов проводились при более высоких температурах вакуумного прогрева $\left(\sim 1800^{\circ} \mathrm{C}\right)$ и меньшем парциальном давлении кислорода $\sim 10^{-6} \mathrm{~Pa}$. На конечной стадии подготовки образца в оже спектрах практически отсутствовали пики углерода.

Дифракционные картины от поверхности вольфрама при термической обработке в вакууме и кислороде появлялись сравнительно рано, когда на поверхности еще находилось достаточное количество углеродных и кислородных загрязнений. Эта стадия рекристаллизации в данной работе не рассматривается.

На рис. 1, $a$ и $b$ показаны картины ДМЭ в период рекристаллизации (рис. 1, $a$ - начало рекристаллизации, рис. $1, b$ - конец рекристаллизации).

В нашем случае на конечной стадии рекристаллизации на поверхность исследованных вольфрамовых лент, как правило, выходила грань (112) с ориентацией, отличающейся от направления прокатки, вдоль которого вырезались образцы. При этом форма дифракционных максимумов на отдельных участках образца могла отличаться друг от друга. На рис. $1, b$ представлена картина ДМЭ от рекристаллизованной поверхности $\mathrm{W}$, на которой каждый рефлекс состоит из трех дифракционных максимумов, отстоящих друг от друга на $\sim 3^{\circ}$. Радиус когерентности электронов в ДМЭ экспериментах $\sim 10 \mathrm{~nm}$ (рис. $1, d)$, а сечение электронного пучка $\sim 0.5 \mathrm{~mm}$. Поэтому полная дифракционная картина на люминесцентном экране низковольтного дифрактометра - это результат сложения интенсивностей от $\sim 10^{8}$ участков поверхности, покрываемых электронным пучком. На рис. $1, d$ показана одна из площадок когерентности. Видно, что на площади $20 \times 20 \mathrm{~nm}$ мы имеем атомногладкую поверхность.

В представленном случае на поверхности вольфрама реализуются два типа периодических структур - на атомном уровне это грань (112) со структурой $1 \times 1$ 

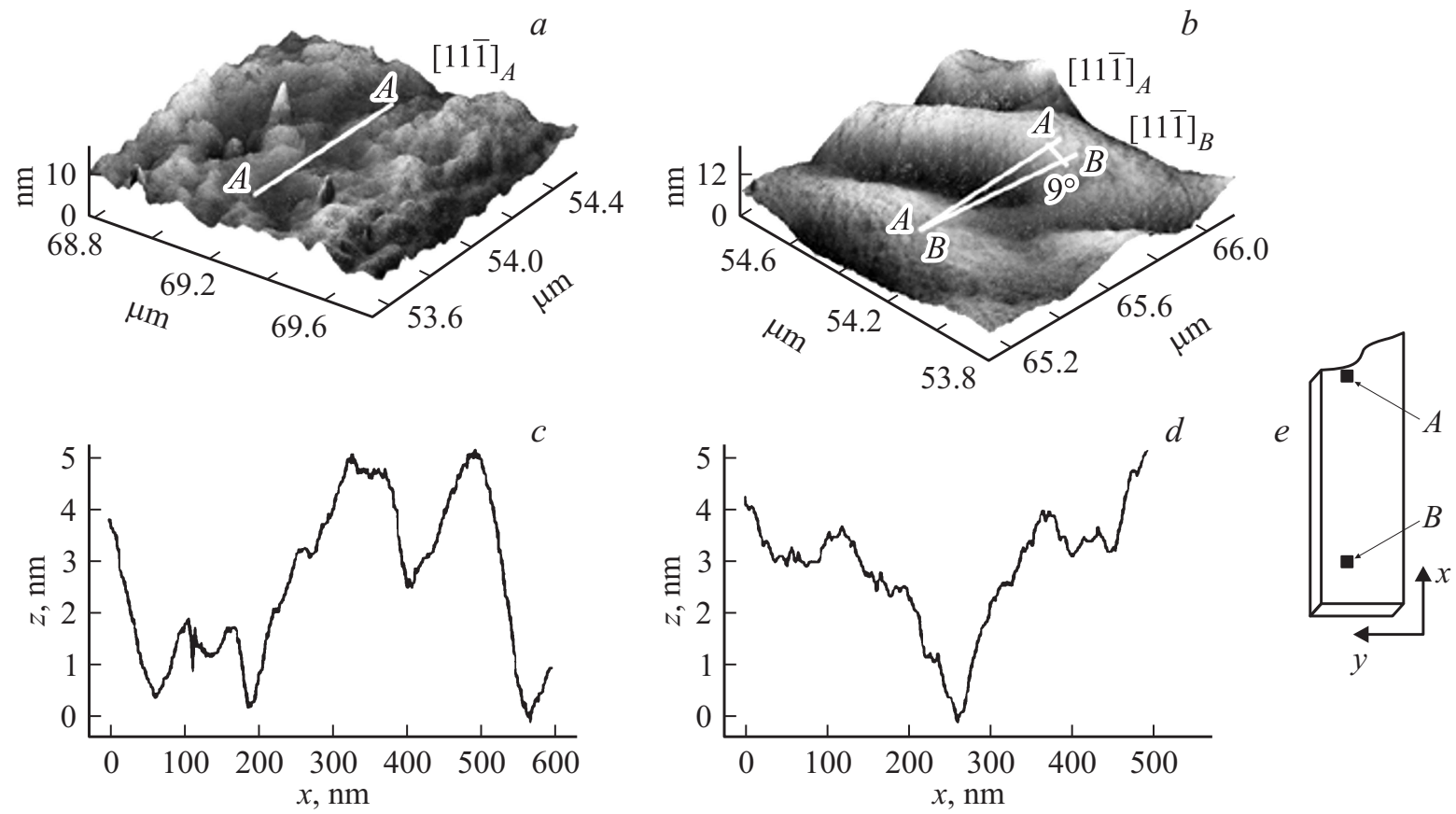

Рис. 2. АСМ топограммы поверхности разорванного образца: $a$ - вдали, $b-$ вблизи от места предполагаемого разрыва образца, $c, d-$ профили сечений, проведенных на этих участках в направлении $[11 \overline{1}], e-$ схема расположения участков на разорванном образце.

и более крупномасштабная периодичность, связанная с расщеплением рефлексов, одинаковая по всему сечению анализирующего электронного пучка, т. е. имеющая макромасштабные размеры.

3.2. Влияние растяжения образцов на атомную структуру и рельеф их поверхности. Зависимость картин дифракции от внешнего напряжения снималась in situ в СВВ. Топограммы поверхности образца, подвергшегося разрыву, снимались методам АСМ в атмосфере сухого азота.

3.2.1. Влияние растяжения на атомную структуpy (метод ДМЭ). Образцы после рекристаллизации (см. рис. $1, b$ и $c$ ) растягивались с плавно возрастающей нагрузкой при вариации приложенного напряжения $\sigma$ от 0 до $90 \mathrm{MPa}$. Для образцов с постоянным поперечным сечением заранее неизвестно место будущего разрыва, поэтому дифракционные картины снимались в нескольких точках вдоль образца, которые давали одинаковые картины ДМЭ. Анализ полученных картин ДМЭ показывает следующее. Наибольшее изменение картин ДМЭ наблюдалось в местах предстоящего разрыва. Картины ДМЭ без нагрузки и картины ДМЭ под нагрузкой вдали от места предстоявшего разрыва практически не отличались друг от друга. Основные изменения на картинах ДМЭ в области разрыва вольфрамовой полоски сводились к изменению расщепления рефлексов от 3 максимумов до 2 (см. рис. $1, b, c, e, f)$. Под влиянием нагрузки (см. рис. $1, b, c)$ происходит разворот дифракционной картины как единого целого на $\sim 10^{\circ}$

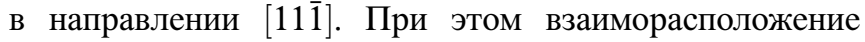
рефлексов осталось неизменным, что свидетельствует о сохранении атомной структуры грани (112). Таким образом, механическое одноосное растяжение привело к изменению „дальнего“ порядка - развороту отдельных блоков [10] в латеральной плоскости и изменению характера периодичности во взаиморасположении этих блоков.

3.2.2. Влияние растяхения на топограммы поверхности. Метод АСМ был применен к образцу уже после его разрыва. Рис. 2 показывает рельеф поверхности образца вдали и вблизи от места разрыва, а также областей на поверхности разорванного образца, от которых были получены картины ДМЭ. На рис. 2, $a, c$ показан рельеф поверхности вдали, а рис. 2, $b, d$ вблизи от места разрыва. Схема расположения мест, от которых получены топограммы поверхности, показана на рис. $2, e$.

Из рис. 2, $a, b$ видно (смотри также рис. $1, b, c)$, что направление $[11 \overline{1}]$,развернулось“ на $\sim 10$ градусов в латеральной плоскости поверхности образца. Это свидетельствует о развороте блочной атомной структуры под нагрузкой вблизи разрыва. Рис. 2, $c$ и $d$ демонстрирует зависимости высоты рельефа $-Z$ в направлении [11 $\overline{1}]$ (см. сечения $A-A$ и $B-B$ на рис. $2, a$ и $b$ ). Из средних значений $\operatorname{tg}$ углов наклона - $\varphi$ участков этих кривых оценены их углы. На рис. 2, $c \varphi \sim 3^{\circ}$, а из рис. $2, d$, $\varphi \sim 1^{\circ}$. Это свидетельствует об уплощении рельефа под влиянием нагрузки.

3.2.3. Фрактальная размерность поверхности. Оценка фрактальной размерности поверхности образца после разрыва была проведена методом покрытий.

Из рис. 2, $a, b$ видно, что несколько систем дефектов различного масштаба накладываются друг на друга. Та- 


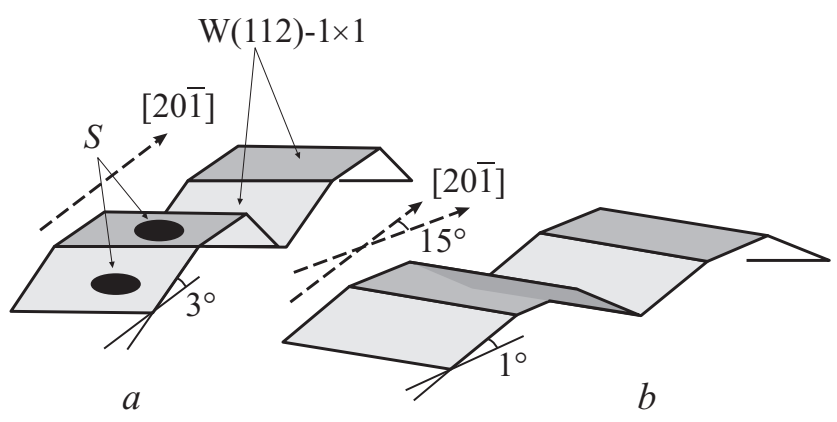

Рис. 3. Схема разворота блочных структур под воздействием нагрузки в латеральной и перпендикулярной ей плоскости: $a-$ при $\sigma=0, b-$ при $\sigma=90 \mathrm{MPa}$. $S-$ пример площадок когерентности, при отражении от которых формируется дифракционный рефлекс (см. рис. $1, d)$.

кие рельефы поверхности характерны для фрактальных структур $[5,11,12]$. Методом покрытий „Box Counting“ с помощью программы „Gwiddion“ оценена общая фрактальная размерность рельефа $-D_{F}$. В нашем случае вдали от разрыва $D_{F}=2.3$. Фрактальная размерность поверхности вблизи от разрыва $D_{F}=2.1$. Уменьшение фрактальной размерности поверхности рядом с разрывом наблюдалось нами и ранее для поверхностей фольг аморфных металлов (см. рис. $4, d$ из [14] и рис. $1, d, e$ из [23]). При этом была показана тенденция к монофрактализации перед ее разрывом.

3.3. Схема разворота блоков грани W (112) под влиянием растяжения. На рис. 3 представлен характер трансформации структуры поверхности, когда на поверхность выходит грань (112) со структурой $1 \times 1$, характерной для химически чистой монокристаллической поверхности.

Выше мы упоминали, что на поверхности существуют атомно гладкие участки размерами $100-200 \AA$ (см. рис. $1, d$ ). На рис. 3 такие участки схематически изображены черными кружками. Оценки разворота блоков $\mathrm{W}(112)-1 \times 1$ в латеральной плоскости, сделанные по изменению направлений $[11 \overline{1}]$ и $[20 \overline{1}]$ (см. рис. $1, b, c$ и рис. $2, a, b)$ дают величину от $\sim 10$ до $15^{\circ}$. Разворот блоков в плоскости, перпендикулярной поверхности, дает величину $\sim 1$ и $\sim 3^{\circ}$ (метод АСМ).

\section{4. Заключение}

В последнее время многие физические явления анализируются на основании процессов самоорганизации. Сочетание методов ДМЭ и АСМ является одним из наиболее перспективных для изучения самоорганизации поверхностных структур.

Поверхность, как межфазная граница, в первую очередь подвержена внешнему воздействию, а ее состояние может изменять прочность на порядки. Методы ДМЭ, ЭОС и АСМ являются одним из наиболее перспективных для создания физической картины процесса разрушения твердых тел.
Для ГЦК-фольг Pt в области предстоящего разрыва происходит развал плотноупакованной грани (111) до аморфного и нанокристаллического состояния. Для ОЦК кристаллических фольг есть отличие между Мо и W.

У Мо в месте предстоящего разрыва кроме разворота структурных блоков, происходит развал плотноупакованной грани (100). На поверхности $\mathrm{W}$ происходит разворот блоков.

\section{Список литературы}

[1] К. Оура, В.Г. Лифшиц, А.А. Саранин, А.В. Зотов, М. Катаяма. Введение в физику поверхности. Наука, М. (2006). $490 \mathrm{c}$.

[2] В.Ю. Витухин, И.В. Закурдаев. ФТТ 39, 1124 (1997).

[3] K. Radican, S.I. Bozhko, Sundar-Raja Vadapoo, S. Ulucan, Han-Chun Wu, A. McCoy, I.V. Shvets. Surf. Sci. 604, 1548 (2010).

[4] Gmelin Handbook of Inorganic and Organometallic Chemistry W Supplement A4. Springer-Verlag, Berlin Heidelberg GmbH. (1993). 279 p.

[5] U. Berner, K.D. Schierbaum. Phys. Rev. B 65, 235404-1 (2002).

[6] J. Emsley. Nature's Building Blocks. Oxford University Press, Oxford. (2001). $262 \mathrm{p}$.

[7] A. Stwertka. A Guide to the elements. Oxford University Press, N.Y. (2002). 247 p.

[8] C.R. Hammond. In: Handbook of Chemistry and Physics. CRC Press, Boca Raton, USA (2000). 4-31 p.

[9] A. Arneodo, E. Bacry, J.F. Muzy. Physica A 213, 232 (1995).

[10] В.Е. Корсуков, С.А. Князев, А.В. Анкудинов, М.М. Корсукова, Б.А. Обидов. ПЖТФ 40, 6, 35 (2014).

[11] В.Е. Корсуков, С.А. Князев, А.Л. Буйнов, М.М. Корсукова, С.А. Немов, Б.А. Обидов. ПЖТФ 39, 8, 55 (2013).

[12] С.А. Князев, В.Е. Корсуков. ФТТ 47, 876 (2005).

[13] С.А. Князев, В.Е. Корсуков, М.М. Корсукова, И.И. Пронин, K. Schierbaum. ЖТФ 77, 8, 140 (2007).

[14] В.И. Бетехтин, П.Н. Бутенко, В.Л. Гиляров, А.Г. Кадомцев, В.Е. Корсуков, М.М. Корсукова, Б.А. Обидов. ФТТ 50, 1800 (2008).

[15] В.Л. Гиляров, В.Е. Корсуков, М.М. Корсукова, И.П. Щербаков. ФТТ 57, 1052 (2015).

[16] В.Е. Корсуков, Г.А. Малыгин, М.М. Корсукова, И.А.Няпшаев, Б.А. Обидов. ФТТ 57, 2463 (2015).

[17] В.Е. Корсуков, С.А. Князев, А.С. Лукьяненко, Р.Р. Назаров. ФTT 38, 113 (1996).

[18] С..А. Князев, В.Е. Корсуков, Б.А. Обидов. ФТТ 36, 1315 (1994).

[19] В.И. Бетехтин, В.Л. Гиляров, А.Г. Кадомцев, В.Е. Корсуков, М.М. Корсукова, Б.А. Обидов. Изв. РАН. Сер. физ. 73, 1506 (2009).

[20] А.Л. Буйнов, В.Е. Корсуков, С.А. Князев, А.В. Анкудинов, В.И. Бетехтин, М.М. Корсукова, С.А. Немов, Б.А. Обидов. Вестн. ТГУ 181835 (2013).

[21] В.Л. Гиляров, В.Е. Корсуков, П.Н. Бутенко, В.Н. Светлов. ФTT 46, 1806 (2004).

[22] В.П. Алехин, О.В. Алехин. Физические закономерности деформации поверхностных слоев материалов. МГИУ, М. (2011). $455 \mathrm{c}$.

[23] В.Е. Корсуков, В.И. Бетехтин, М.С. Варкентин, В.Л. Гиляров, А.Г. Кадомцев, М.М. Корсукова, Б.А. Обидов. ФТТ 55, 729 (2013). 